This item was submitted to Loughborough's Research Repository by the author.

Items in Figshare are protected by copyright, with all rights reserved, unless otherwise indicated.

\title{
Do connected town-centre shopping journeys improve town-centre patronage?
}

PLEASE CITE THE PUBLISHED VERSION

https://doi.org/10.1108/IJRDM-05-2020-0178

PUBLISHER

Emerald

VERSION

AM (Accepted Manuscript)

PUBLISHER STATEMENT

This paper was accepted for publication in the journal International Journal of Retail and Distribution Management and the definitive published version is available at https://doi.org/10.1108/IJRDM-05-2020-0178

LICENCE

CC BY-NC 4.0

\section{REPOSITORY RECORD}

AbedRabbo, Majd, Cathryn Hart, and Fiona Ellis-Chadwick. 2021. "Do Connected Town-centre Shopping Journeys Improve Town-centre Patronage?". Loughborough University.

https://hdl.handle.net/2134/13713301.v1. 
International Journal of Retail \& Distribution Management

\section{Do Connected Town Centre Shopping Journeys Improve Town Centre Patronage?}

\begin{tabular}{|r|l|}
\hline Journal: & International Journal of Retail \& Distribution Management \\
\hline Manuscript ID & IJRDM-05-2020-0178.R3 \\
\hline Manuscript Type: & Research Paper \\
\hline Keywords: & $\begin{array}{l}\text { Shopping Experience, Town Centre, Patronage, Digital Integration, } \\
\text { Connected Experience }\end{array}$ \\
\hline \multicolumn{2}{|l}{} \\
\hline
\end{tabular}




\title{
Do Connected Town Centre Shopping Journeys Improve Town Centre Catronage?
}

\begin{abstract}
Purpose - This study explores the role played by digital channel integration in the town centre shopping experience. It also explores how customers perceive the role of digital in the town centres shopping journeys, improves shopping experiences, and encourages positive future patronage behaviour. Ultimately, the aim is to identify the likely implications of a connected shopping experience on patronage intentions.
\end{abstract}

Design/methodology/approach- A qualitative research design using focus groups to explore customers' perceptions of connected town centre shopping experiences was deployed. Then, data was analysed using thematic analysis to identify overarching themes.

Findings - Digital integration has the potential to serve discreetly different functions in the town centre context: create interconnected information channels, facilitate improved connected shopping experiences, generate positive perceptions of a town, which subsequently shape future patronage intentions. The study also revealed expectations of digital integration are yet to be fully realised in the town centre context and there are tensions between physical and digital domains to be overcome if digital integration is to positively influence patronage intentions.

Research Limitations - The nature of exploratory research tends to pose questions and open out a problem rather than provide definitive answers. This study has sought to highlight key issues and also provide points of departure for future studies. The significance and generalisability of the results are limited by the size and nature of the sample.

Originality/value - This study provides theoretical contribution to the town centre literature by expanding our understanding of consumers perceptions of the role of digital integration in shopping journey experiences and unlocks insights into its potential impact on future patronage intentions. Practical considerations for integrating digital in the town centre to create more connected shopping experiences.

Keywords Shopping Experience, Connected Experience, Digital Integration, Town Centre, Patronage Paper type: Research paper 


\section{Introduction}

Historically, town centres are important shopping destinations in the UK, but High Streets are being recalibrated through the adoption and integration of digital channels by businesses, service providers and other stakeholders. Despite this widespread adoption of digital technologies, town centre managers make limited investments in improving their town's digital presence and communication channels (Housing, Communities and Local Government Committee, 2019). Perhaps this is explained by consumer demand for digital channels and the impact on shopping experiences being poorly understood at the level of the town-centre. While researchers have widely studied how complex High Street environments stimulate consumer engagement and enhance their experiences when visiting towns for various shopping journey purposes (Stocchi et al., 2016), to the authors' knowledge, none has empirically tested how digital channels might influence consumer shopping experiences in this context. This scarcity of research into the integration of digital technologies is surprising given that most town centre journeys are shopping related (Hart et al., 2013). Especially, when considering growing evidence that integrating physical and digital channels can better satisfy consumer demands by providing contextual information at decisive moments of truth in the customer's shopping journey (Chaffey and Ellis-Chadwick, 2019; Lemon and Verhoef, 2016).

Alongside this, high street performance in 2018 showed significant drop in customers' footfall in UK town centres by $8.1 \%$ leading to an increase in the vacancy rates by $11.1 \%$ from the previous years (Housing, Communities and Local Government Committee, 2019). Given these concerns, research exploring integration of digital channels on the town centre landscape becomes critical to arrest decline and avoid places becoming 'ghost towns' (Holder, 2019; Housing, Communities and Local Government Committee, 2019). Arguably, digital integration is becoming even more important for town centres following the impact of the COVID-19 pandemic which, has demonstrated the volatility of brick and mortar stores sales as customers come to rely heavily on online shopping. Reports suggest consumer e-commerce grew by over 40\% since March 2020 and multi-channel retailers saw an increase closer to $70 \%$, suggesting changing consumer behaviour when choosing where to shop (Rigby, 2020). With growing concerns that customers' patronage may not return to pre-pandemic levels, understanding the impact of digital integration in town centres becomes more urgent to maintain the viability of towns as retail destinations.

The following issues are recognised as central to understanding digital integration and provide a point of departure for this exploratory study:

i. To what extent do digital channels (in a town centre) offer synergies with the physical place, and does this enhance or limit customers' ability to migrate across channels to achieve different shopping goals (Herhausen et al., 2015; Verhoef et al., 2015)? 
ii. Does the existing level of integration of digital channels (in a town centre) hinder shopping journeys, and impact negatively on consumer experiences if they are unable to easily achieve their shopping goals conveniently (Wrigley et al., 2015)?

iii. To what extent does digital channel integration deliver benefits such as reduce spatial and temporal constraints and reduce transactional costs of shopping in the physical place (DemkoRither and Ter Halle, 2015)?

iv. How can digital integration impact (on a town centre) on patronage behaviour (Betzing et al., 2018; Verhoef et al., 2015; El Azhari and Bennet, 2015)?

Therefore, this paper is a first step in understanding how customers perceive digital integration in town centres. It considers the scope for this integration in developing a connected town centre shopping experience and the likely implications of shopping experience on patronage intentions. The paper is structured as follows: first, it explores theoretical background on connected shopping experience in the literature. Then, the methodology and analysis of the results are highlighted. Finally, a discussion is provided alongside theoretical contributions, managerial implications and future research direction.

\section{Theoretical background}

\section{Disrupted dynamics of the shopping experience}

Researchers have discussed how the advancement of digital retailing disrupted the dynamics of shopping experiences (Dennis et al., 2016; Verhoef et al., 2015). For instance, customers' expectations and behaviours towards the physical store have altered due to increased accessibility to a plethora of online information across multiple channels beyond those of the retailer (Lemon and Verhoef, 2016; Cao and Li, 2015; Pauwels and Neslin, 2015). These actions facilitated new shopping behaviours such as webrooming and showrooming to make better shopping decisions (Pantano and Priporas, 2016; Verhoef et al., 2007). Consequently, customers' expectations from the shopping experience extended beyond a single channel and retailer, making it more dynamic and difficult to manage (Verhoef et al., 2015). The possibilities afforded by digital technologies have influenced both retailer and consumers. Since 2005, many large retailers' have made investments in digital channels aimed at developing superior customer experiences and levels of service online (Lemon and Verhoef, 2016; Doherty et al., 2015). This is stimulated by customers' demand for a multisensorial and interactive experience that entertains, stimulates and emotionally affects them (Verhoef et al., 2009). As such, Terblanche (2018) argues a memorable shopping experience is associated with a distinct competitive advantage that influences existing and future customers' patronage intentions. 
A body of research from the customer perspective has examined customer experiences with retailers following digital integration (Pantano and Priporas, 2016; Herhausen et al., 2015; Cao and Li, 2015). But this needs extending to explore at a macro level (such as town centres) and to increase understanding of the effect of digital integration on the shopping experience and patronage behaviour (Housing, Communities and Local Government Committee, 2019; Stocchi et al., 2016; Wrigley et al., 2015). This is equally important because shopping experience is personal and informed by interaction between the customer and stimuli (from the retail environment) across each stage of the decisionmaking process (Jain et al., 2017; Lemon and Verhoef, 2016). Customers evaluate the totality of their interactions with the physical retail touchpoints to create a perception of the shopping experience that guides their patronage intentions (Verhoef et al., 2009). These perceptions are moderated by a customer's ability to achieve their goals from interacting with a specific channel/retailer (Verhoef et al., 2009). With the image of town centre changing beyond a pure retail destination (Hart et al., 2013), understanding customers' perceptions of digital integration on their connected town centre shopping experience could unlock insights into patronage issues for better place management.

\section{Connected shopping experiences}

With the advancement of digital retailing, customers' expectations from retail settings extended beyond physical interactions with the retail place (Dennis et al., 2016; Verhoef et al., 2015). Digital retailing started empowering customers with information to use during the decision-making journey, which altered their expectations and behaviours (Cao and Li, 2015). Nowadays, depending on their shopping goals, many customers prefer to shop across different physical and digital channels to create a connected shopping experience, which increases the perceived value of their shopping decisions (Betzing et al., 2018; Brynjolfsson et al., 2013). Studies found that integrating digital channels and technologies in retailing influence purchase intentions positively (Watson et al., 2018; Pantano and Priporas, 2016). Digital retailing increases the quality of shopping experience by enabling personalised retail services that facilitate the interaction process (Hoffman and Novak, 2015). Further, it allows constant availability and interactivity between the customer and retailer to conduct the transaction at the customer's convenience beyond the physical store, which reduces transactional costs of shopping (such as time and effort), thus enhancing the shopping experience (Frasquet and Miquel, 2017; Demko-Rihter and Ter Halle, 2015).

A connected shopping experience has also been found to have a positive effect on customers' search, purchase and willingness to pay intentions (Herhausen et al., 2015; Pantano and Priporas, 2016). These researchers argue by digitally linking the physical store, customers' experienced higher positive perceptions of service quality and reduced levels of perceived risk in their decision-making, which led to an improvement in perceived experience overall. The effect of digital channels integration on the physical store extends to other attributes including customers' order size and purchase frequency (Cao and Li, 2015; Pauwels and Neslin, 2015). In the high street context, scholars found a positive effect of 


\section{Digital Integration and Patronage intentions}

Research suggests a lack of a connected shopping experience in town centres may have negative implications on patronage. For physical places to survive, Rigby (2011) emphasises the need to have "an integrated sales experience that melds the advantages of physical stores with the information-rich experience of online shopping" (p.4). This statement is supported by recent work demonstrating the advantages of channel synergies across the decision-making process (Anderl et al., 2016; Fornari et al., 2016). As we move towards an omnichannel strategy, scholars emphasise the need to take a customercentric approach to online-offline channel integration to satisfy different customer goals (Palmatier et al., 2020). Indeed, the limited digital integration in town centres creates spatial and temporal constraints where customers remain unable to interact with the town centre without physically being there, thus limiting their goal fulfilment process (Demko-Riher and Ter Halle, 2015). Accordingly, customers may face challenges in fulfilling their shopping goals, incurring significant monetary and temporal costs. (El Azhari and Bennet, 2015; Wrigley et al., 2015).

The relationship between the town centre customer experience and the likelihood of revisiting the town centres are noted in the literature (Stocchi et al., 2016; Hart et al., 2013). However, these studies focused on customers' physical interactions with the town centre, with limited consideration of the effect of digital on the town centre customer experience. Reports and academic research raised the call for researching the effect of digital on the Town Centre Customer Experience (Wrigley et al., 2015). At a business level, Pantano and Timmermans (2014) argue "the emerging idea of smart retailing would reflect a particular idea of retailing, where firms and consumers use technology to reinvent and reinforce their role in the new service economy, by improving the quality of shopping experiences" (p.102). Thus, town centres are encouraged to rethink their digital retail offer to maintain their economic and sociological contributions

Additionally, limited focus on the role of digital channel integration in previous studies highlights the importance of further exploration of the connected shopping experience and its likely impact on town centre patronage. Creating a seamlessly connected experience across the retail channels can help retailers to maintain their customers and improve performance (Jocevski et al., 2019). Kim 
(2002) argued, retailers should explore how customers are shopping in the digital domain to create similar experiences in the physical place. But also, to understand the scope to transcend the limitations of either physical or digital channels by connecting them together to deliver much more informed shopping journeys. As such, this exploratory study seeks to attain insights into the forms of digital integration that can be leveraged in the town centre to create a connected shopping experience. This study addresses the following specific research questions:

RQ1: How do customers perceive digital integration can be implemented in the town centre shopping journey to enhance the shopping experience?

RQ2: What is the likely effect of a connected shopping experience on town centre patronage intentions?

\section{Methodology: Exploring the connected shopping experience in a town centre}

This study applied an exploratory qualitative approach to probe the connected shopping experience in a town centre context. This approach develops insights into participants perceptions of constructs and variables of interest (Hair et al., 2017) and allowed us to delve into their connected shopping experiences.

Three focus groups were administered in an East Midlands town centre, which represents an average market-town in the UK with a population over 60,000 (Taylerson, 2017). Additionally, the town has a university with 3869 employees and 17,077 students from different regions across the UK (Loughborough University, 2019), which adds to the richness of the attained data due to participants' diversified shopping experiences across the country. A purposeful sampling technique was used to recruit participants from different demographic profiles in a timely manner. Participants were recruited following a research call through emails and social media platforms.

Each focus group involved 8-12 participants with a total of 29 participants taking part in the study. Participants ages ranged from 18-60 years old, with an average of 34.7 years and a representative spread of socio-economic profiles (AB, C1, C2 and DE). There were more females (18) than males (11) in this study, which is consistent with the demographic split of this town and previous town centre research (Stocchi et al., 2016). As noted earlier, a few participants have lived and have shopped in various towns across the region. The diverse shopping experiences of those participants enabled the researcher to elicit insights about the connected town centre shopping experience across several towns.

Each session lasted 75 minutes and was moderated and recorded by the research team. Focus groups were semi-structured, and participants were guided through the interview schedule. Open-ended questions allowed participants to freely express their shopping experiences using their own words and engage in an interactive discussion. Thematic analysis based on Braun and Clark (2006) was applied to extract latent meanings behind participants' words. With limited understanding of the connected town 


\section{Results}

\section{1) How do customers perceive digital integration can be implemented in the town centre shopping journey to enhance the shopping experience?}

Focus group findings suggest customers mainly perceive their shopping experience in terms of interactions with physical touchpoints of the town centre including; assortment of shops, range and availability of products, transport, accessibility and layout of the town centre, as well as social interaction with other customers, shopkeepers, and leisure facilities such as cafes. Participants reported different feelings and sentiments towards an interaction with one or all these touchpoints across their shopping visit:

My shopping experience would be judged by what the town can offer to me such as good range of brands and products, cheap parking and clean routes...It will either be a happy experience or a bad experience [Female, 31-40, C1].

Sometimes I have positive experience and sometimes not. It all depends on each visit. For example, if I go into town and I am able to find a convenient parking, it will be a pleasant one. Unfortunately, most of the times you don't find good products and end up wasting your time walking down empty stores and wasting your money on parking [Female, 31-40, AB].

Having established common understanding of the town centre shopping experience across the focus groups, participants were then asked whether they were aware and/or have interacted with any town centre's digital touchpoints during their town centre shopping visits. None of the participants 
reported a previous interaction with any digital touchpoint of the town centre and had little or no awareness of its existence. Moreover, some participants mentioned their lack of interest in searching for digital touchpoints as they were familiar with the town centre, and believed digital information would not add value to their knowledge:

I never heard of any online for the town centre. What can it offer to me? I know the town centre inside out, so it doesn't come to me [Male, 18-25, DE].

Do they exist? I have never heard of any online website for [town] in my life. Won't use it anyway because I know the town thoroughly [Female, 27, C1].

I wouldn't think of using them because I know everything in the town so I would just go and get what I want easily [Female, 40, AB].

Methodologically, this outcome enriched discussion of participants' perceptions of digital integration in the town centre and they freely expressed their views (with minimal bias from their peers as they had equal knowledge of the research topic).

It is hard to imagine how it can be used in my shopping visit. Maybe just like a shopping mall? For example, when I go to a shopping mall, I can check what stores they have, any offers, parking costs, and any events they are running [Female, 18-25, C1].

You know those displays in shopping centres? I've recently been to Westfield and all you need to do is touch it, search for information on the shops you want. It also has a map that's quite useful. I think we can have such thing in town centres, especially in here where we seem to have more than one centre [Female, 31-40, C1].

As the majority of the participants were not aware of the study town's digital channels, they discussed the potential value and role of digital channels through things they were familiar with e.g., websites, social media and mobile application, in order to assess how they might gather vital shopping information about a town centre. These digital channels were seen as useful in informing their shopping visits to different retail locations and provided detailed information such as variety of stores, opening hours, promotional events and more. Many acknowledged the value of digital information insights in planning and informing shopping journeys and facilitating successful achievement of shopping goals. They also recognised the limitations placed on physical shopping journeys when such information is missing:

When I shop online, I can find every store I want, every product with the right price within few clicks. Maybe if such a website exists for a town centre, then it can help me learn more about the stores in the town and if any offers exist. At least I wouldn't waste my time going there for luck [Female, 26-30, C1].

The issue is town shopping is inconvenient. You don't find what you want, and if you do, you find it at a higher price. Parking is a problem that needs attention. I don’t know how digital can be a solution but 
maybe a website or a mobile application like Harrods app can help to gather all information of the town in one place [Male, 31-40, AB].

Despite being driven by physical shopping experiences the consensus amongst participants was; physical town centre shopping can be a relatively poor experience. Memories of previous unsuccessful shopping trips remind customers of inconveniences and significant costs associated with unsuccessful shopping trips. Some participants revealed over-reliance on their familiarity and knowledge of the town centre retail offer.

Last time I went looking for a suit in the town centre for a job interview the next day. I always went to this store next to McDonalds because they are of good quality. When I got to town, the store had a sign that they are closed permanently. I was disappointed because I could have gone somewhere else like [regional city] and bought one [Male, 41-50, AB].

Although participants had limited experience of town centre digital integration, they used their wider shopping experiences; online and in shopping malls to suggest how the town centre might improve information flows through digital channels. These findings offered insights how the participants might value (or not) the town's digital channels and touchpoints had they used these channels. Participants acknowledged the potential value of pre-shopping journey information believing that digital channels can provide relevant and timely information to plan their shopping journey more effectively and reduce the associated transactional costs. Digital channels are perceived to fulfil a complementary role to the physical shopping journey. There was agreement amongst the three groups of the positive effect of digital integration on their town centre shopping experience:

Knowing what I can get without going there will save me a lot of time and effort [Male, 18-25, C1].

I think it would be helpful for many of us to know more about independent retailers that operate in the town [Female, 26-30, C1].

I will feel a lot better about shopping in [town] if I can get a similar experience to that online [Female, $18-25, \mathrm{C} 1]$.

Importantly, participants repeatedly cited the need for freely accessible Wi-Fi, to help overcome connectivity issues, when shopping. They also suggested when mobile phone signal coverage is "poor", "weak" and "limited" in certain areas of a town, this hinders their ability to make better shopping decisions:

The reason I shop online is that I can get a bargain by comparing the prices. When I am in town, sometimes I struggle to do so because I don't get good signal on my phone, so I end up nipping into a café to use their Wi-Fi and check the prices [Female, 31-40, AB].

I use the internet to get advice from my family and friends when shopping. If I can't get online, I won't be able to make a good decision, so I end up leaving [Female, 18-25, DE). 
I remember once I was buying clothes for my sister in-law and I was sending my husband photos of it. I ran out of internet signal and the store had no Wi-Fi to connect to. I would have avoided this poor experience if I was shopping in a mall because they have free internet there [Female, 31-40, C1].

Consequently, Wi-Fi connectivity is perceived to be an expected tool of digital integration to bridge the gap between the physical and digital domains. It not only connects customers to other channels and information, Importantly, it connects them with their social circle to seek reassurance in their choices.

2) What is the likely effect of a connected shopping experience on town centre patronage intentions?

Having identified the different forms of digital integration, participants reflected on the likely effect of a connected shopping experience on their patronage intentions. First, they agreed that different shopping experiences influence revisit, spend or dwell intentions differently. Product assortment, choice and selection were primary considerations, followed by external factors for example, weather conditions, parking, local events:

Last time I shopped in [town] was terrible. Barely any good stores let alone the weather. I don't like to go there unless I really have to [Female, 18-25, C1].

When I went there last time it was nice. I managed to get a good parking spot for cheap. I got everything I wanted in one go rather than going in and out to move the car. The market was in town so I stayed for a little longer and ended up buying more things from the market [Male, 31-40, C2].

I don't enjoy visiting [town] for shopping because you cannot get anything. Market days are good because they create a vibrant atmosphere in the town so you would enjoy spending time and money there. Otherwise, it is waste of time [Female, 41-50, AB].

When asked about the effect of a connected shopping experience on their future patronage, most participants reported positive intentions towards shopping in the town centre if a digital integration existed. This suggests the utility of the shopping visit could be improved by accessing information about town centre shopping prior to and during their shopping visit. They also agreed efficacy of the shopping journey could be increased by knowing what stores, products, prices, are available in the town centre when planning to visit and thus reinforce their image of a town as a shopping destination.

Many participants had more nuanced views of how digital channel integration might positively influence patronage behaviour by facilitating their connection to the town centre without being physically present.

My issue in this town is that I can't get what I want, for the price that I want. But maybe if I know what is available in the town centre through a website, then I guess I will be tempted to give it a try. It will 
A few participants had negative perceptions on the potential effect of a connected shopping experience on their patronage intentions. They perceived that the town has a "poor" and "insufficient" retail offer, and 'Dead and Empty' atmosphere which was a structural problem that could not be solved by digital integration.

I don't think it will impact my decision to go there at all. The problem is the town is dead and empty. Having Wi-Fi or a website will not solve the problem. In fact, it might be off putting for people because they will know how poor the town is before going there [Male, 26-30, C2].

Although I don't see it happening anytime soon, but let's say it exists, I think I will be more willing to try and shop there again. [Female, 26-30, C1].

I know the town inside-out and the disappointment is there. I don't see the value of shopping in the town anymore. [Female, 31-40, AB].

The town has poor variety of shops that are often overpriced, inadequate parking options and unpleasant appearance. For digital to be helpful, town centre should be improved first. We can't pay expensive parking and waste time just to enjoy Wi-Fi. In fact, digital information will only push me further because it will show me how poor my town centre is [Male, 31-40, AB].

The results revealed shortcomings of the physical offer of the town which, in turn limited the scope of digital channels to deliver improvements to influence patronage intentions. Providing digital information in a timely way to create opportunities for individuals to plan their shopping better was perceived as a strong positive. Moreover, there is potential for a halo effect of shoppers' perceiving the town to be more convenient and the shopping experience in the town more memorable. Results also supported the idea that positive shopping journeys outcomes are more likely to yield positive future patronage intentions than negative experiences. But some participants were cynical about when digital integration might happen in a meaningful way in the town. Interestingly, the physical touchpoints of the town centre, key drivers of shopping journeys, (including assortment of shops, range and availability of products) were cited as a structural barrier which no amount of digital channel integration could overcome. 


\section{3) Emerging Findings: The moderating role of shopping goals on the perceived connected shopping experience and patronage intentions.}

Study participants had different viewpoints on the effect of digital channels on the connected town centre shopping experience. These differences were attributed to customers' purpose of shopping in the town centre. This finding is consistent with Palmatier et al., (2020) arguments on the role of goals in customers' interactions with multiple channels. These researchers found, customers interested in browsing or spending recreational time shopping, perceive a positive effect of developing integrated digital channels and technologies on town centre shopping experience. Study participants argue contextual information allows them to shop online and offline at the same time whilst being in the town centre, can help them make better shopping decisions by comparing prices, and enable physical examination of products, and or seeking alternatives.

Shopping online is nice because you can browse several stores in few clicks. I think if I go to the town just to browse, then I'll benefit from a website to view information available about several stores in town when I am there. Internet accessibility will definitely help me when I want to read more about a product [Female, 18-25, C1].

Participants believe digital integration could influence their behaviour and deter them from shopping in the town centre if the product/service was not available in the town. Product categories also influence common perception of digital integration.

It would only put me off. If you want to buy specific item and you can't find that it exists in town, then you won't go there at the first place. I feel this would only expose the bad selection of stores and services in these rundown places. Online is the way forward [Male, 31-40, AB].

It could go both ways. For clothing stores, they will be empty as people will realise there is no range of products there so it's a waste of time. At least people now go there hoping something interesting could pop-up. If you want something else like groceries or vape, then it would be excellent as we have an excess of these stores there [Female, 31-40, AB].

\section{Discussion and implications: Digital Integration in Town Centres- where are we now?}

Town centres face difficulties ahead. The trading environment is increasingly uncertain due to the COVID-19 pandemic and shopping online is expanding rapidly since the outbreak of the pandemic in March 2020; e.g. from 20\% to 32\% of total retail sales (ONS, 2020). Furthermore, shoppers have developed greater anxieties about the risks associated with shopping in physical environments (Federman, 2020). Arguably, there has never been a more important time for successful digital integration, which can provide information to shoppers, enable purchasing and in doing so contribute to town centre recovery. From the issues raised at the beginning of the paper, this study has found a distinct lack of integration between physical and digital channels and negative perceptions of how this 
missing facility in a town centre can limit customers' ability to switch between channels, which hinders the achievement of shopping goals. This finding supports Herhausen et al. (2015) and Verhoef et al. (2015) in terms of the limiting effects when synergistic digital integration is absent. Lack of integration of digital channels has also impacted negatively on shopping experiences, even more than anticipated, as shoppers were found to be over reliant on their memories of physical shopping experiences and had little regard for the town's digital information. This study referred to the work by Demko-Rither and Ter Halle (2015) but found the intangible benefits were limited to experiences associated with use of free town Wi-Fi rather than reducing spatial and temporal constraints and reduction of the transactional costs of physical shopping. Evidence of positive influence on patronage intentions as suggested by Betzing et al. (2018), Verhoef et al. (2015), and El Azhari and Bennet (2015) was not found but the study participants recognised the potential to achieve such gains in the town context based on their experiences of shopping in other locations.

How has this study advanced understanding of connected town centre shopping experiences and how can towns enhance shopper journeys through digital integration and in doing so ensure longterm survival?

\section{1) Bridge the gap between digital and physical channels}

There appears an assumption that because adoption of digital technologies is so widespread it should integrate seamlessly into shopper journeys just by being there. In our study, town centre customers still view their shopping experience in terms of interactions with the physical touchpoints rather than digital ones, hence town centre digital channels were perceived as low priority and low value. Powerful memories of previous physical shopping trips dominated consumer perceptions and when interlaced with familiarity of a place, it further downgraded the perceived usefulness of digital channels. Town centre management need help to address the balance by using digital to change perceptions of physical touchpoints:

i. Shoppers encounter drivers and barriers at every stage of their shopping journeys from planning to post-visit (Lemon and Verhoef, 2016). Identifying which information they need and when in their journey will enable towns to become a valued source of information. By showcasing the physical touchpoints (including assortment, parking spaces and entertainment events) via a town's website, mobile applications or using social media at different stages of their journeys, it will enable customers to discover new parts of the town and shift from habitual journey behaviours (Hart et al. 2014). In so doing, shoppers will also remain connected to their own digital domain within the current retailing environment (Verhoef et al., 2015). Here the real value to the shoppers is relevance, and encouraging social interaction with their friends, and influencers at every stage of their shopping journey. 
ii. Creating awareness of digital channels and touchpoints and demonstrating the value to the shopper. Town centre apps already provide product ranges, store availability, and trails but are clearly not easily discoverable to all shoppers who may need educating to their value. Marketing tools could be used to inform and change perceptions about both the retail and digital touchpoints for the town. For example, using promotional offers, town centre management can encourage users to download parking and public transport apps to link access to the town. Regular virtual 'events' advertised via town centre apps e.g. linking local independent retailers, producers, online and offline, will educate local customers to the hidden, diversified assortment available in that town, while supporting local businesses online. Sector based e.g. virtual food events could similarly link large supermarkets with local producers, providing online blogs and competitions. Likewise, With the emerging risk of COVID-19 spread, a town centre app may highlight the hotspots and busy areas of the town, which would help people be reassured of when to visit the town safely and conveniently.

\section{2) Harness the potential of digital integration}

Understanding more about how shoppers plan their journeys, the touchpoints which inform their decision-making and bridging the gap between digital and physical channels, could help towns to become an integral part of the shoppers' digital domain. Depending on the purpose of their shopping trip, at a basic level shoppers' need access to dynamic information about the physical touchpoints (Assortment, Layout, Accessibility and Leisure), and digital touchpoints (mobile application, Web sites, Social media channels, e-commerce platforms of the businesses in the town). These need to be in place for customers to attain convenience in the shopping journey. Further, for customers seeking hedonic shopping visits, digital has the potential to add exciting, discoverable experiences through gamification, VR and AR and other innovations, which can allow experiences such as virtual shopping visits in the pre and post visit stages of the town centre journey.

\section{3) Create a pull effect using digital channels to drive patronage}

Using digital touchpoints enables towns the opportunity to uncover experiential value to the shopping experience (El Azhari and Bennet, 2015). Shopping experience is positively affected as a result of the multiple channel shopping behaviour facilitated by digital integration (Pauwels and Neslin, 2015; Herhausen et al., 2015). This in turn can influence customers' patronage intentions towards the retail environment (Terblanche, 2018). Consistently, the study's findings suggest different perceptions of the shopping experience yield different patronage behaviours in the town centre. Participants indicated that negatively perceived shopping experiences in local town centres influenced negative 


\section{Conclusions, Limitations, and future research}

Drawing from consumer insights, this study enriches the town centre literature and breaks new ground by 1) understanding the role of digital channel integration in the (town centre) shopping experience, 2) highlighting the effect of digital integration on the perceived shopping experience and patronage intentions; 3) considering the importance of channel integration on future patronage intentions. As such this study extends the town centre literature by answering the calls for research on this topic (Stocchi et al., 2016; Wrigley et al., 2015).

This study has also provided managerial implications towards integrating digital channels and technologies to improve the perceived value of shopping in town centres. In the emerging economic environment, creating digital channels can be a cost effective first step to overcome customers' concerns regarding the transactional costs of shopping locally. With the change in consumer expectations of a connected shopping journey (Palmatier et al., 2020; Verhoef et al., 2015), integrating digital channels will inform town centre users' expectations and perceptions of their shopping journey. This in turn yields positive experience and patronage behaviour. Likewise, given the likely consequences of COVID-19 pandemic on consumer sense of safety and social interactions, bridging the gap between the physical and digital town can reduce the spatial constraints, which in turn will allow the customer to assess the layout and atmospheric cues of the town (such as traffic, queues and hot spots) before visiting there.

Despite the richness of the data and insights collected during this study, there are limitations to the findings. Whilst small sample sizes are suitable for exploratory research (Churchill, 1999), the results of this research cannot be generalised. Customers across other regions in the UK may have different perceptions of a connected shopping experience due to situational factors such as location, retail offer and available digital offer. Therefore, future work could build on this work across other regions to extend our knowledge of this construct in the town centre context. A subsequent study may include quantitative data across different regions and/or countries to validate and generalise the findings 
proposed in this research. It would be interesting to empirically test the relationships between the digital touchpoints and the shopping experience construct to attain detailed insights into the role of digital interactions in changing customers' perceptions of the physical touchpoints and patronage intentions. The outlined effect of shopping goals and product categories on the perceived connected shopping experience and patronage intentions would offer an interesting perspective and researchers are encouraged to use multigroup analysis to capture the effect of digital integration on the perceived shopping experience across different shopping goals.

\section{References}

Anderl, E., Schumann, J.H. and Kunz, W. (2016), "Helping firms reduce complexity in multichannel online data: a new taxonomy-based approach for customer journeys", Journal of Retailing, Vol. 92 No. 2, pp. 185-203.

Betzing, J.H., Beverungen, D. and Becker, J. (2018), "Design principles for co-creating digital customer experience in high street retail", In edited by Drews, P., Funk, B., Niemeyer, P. and Xie, L. (Ed.s), Tagungsband Data Driven X --- Turning Data into Value --- Band V MKWI '18, Leuphana Universität Lüneburg, Lüneburg, pp. 2083-2094.

Braun, V. and Clarke, V. (2006), "Using thematic analysis in psychology", Qualitative research in psychology, Vol. 3 No. 2, pp. 77-101.

Business Wire (2019), “Tech. 2019: Global Retail Tech Spending To Top \$203 Billion This Year”, available at: <https://www.businesswire.com/news/home/20190530005528/en/Tech.2019-Global-Retail- Tech-Spending-Top $>$ [accessed 3 February 2020].

Cao, L. and Li, L. (2015), “The Impact of Cross-Channel Integration on Retailers' Sales Growth", Journal of Retailing, Vol. 91 No. 2, pp. 198-216.

Chaffey, D. and Ellis-Chadwick, F. (2019), Digital marketing: Strategy, implementation and practice, $7^{\text {th }}$ ed., Pearson, New York:NY.

Demko-Rihter, J. and Ter Halle, I. (2015), "Revival of high street retailing-the added value of shopping apps", Amfiteatru Economic Journal, Vol. 17 No.39, pp.632-645.

Dennis, C., Alamanos, E., Papagiannidis, S. and Bourlakis, M. (2016), "Does social exclusion influence multiple channel use? The interconnections with community, happiness, and wellbeing", Journal of Business Research, Vol. 69 No. 3, pp. 1061-1070.

Doherty, N.F., Shakur, M. and Ellis-Chadwick, F. (2015), "The role of e-service quality management in the delivery business value", Journal of Retailing and Consumer Services, Vol. 27, pp.52-62.

El Azhari, J. and Bennett, D. (2015), “Omni-channel customer experience: an investigation into the use ofdigital technology in physical stores and its impact on the consumer's decision-making process". In: XXIV AEDEM International Conference, London, UK.

Federman, J. (2020), “Coaxing an Anxious naion back on the High Street”, Business Reporter, available at: https://business-reporter.co.uk/2020/06/29/coaxing-an-anxious-nation-back-on-to-thehigh-street/ (accessed: 20 $0^{\text {th }}$ October 2020). 
Fornari, E., Fornari, D., Grandi, S., Menegatti, M. and Hofacker, C.F. (2016), “Adding store to web: migration and synergy effects in multi-channel retailing", International Journal of Retail \& Distribution Management, Vol. 44 No. 6, pp. 658-674.

Frasquet, M. and Miquel, M.J. (2017), "Do channel integration efforts pay-off in terms of online and offline customer loyalty?", International Journal of Retail \& Distribution Management, Vol. 45 No. 7-8, pp. 859-873.

Hair, J. F., Celsi, M., Ortinau, D. J., and Bush, R. P. (2017), Essentials of marketing research, $4^{\text {th }}$ ed., McGraw-Hill Education, New York, NY.

Hart, C., Farrell, A. M., Stachow, G., Reed, G. and Cadogan, J. W. (2007), "Shopping Experience Enjoyment: Impact on customers' Repatronage Intentions, and Gender Influence”, The Service Industries Journal, Vol. 27 No. 5, pp. 1-46.

Hart, C., Stachow, G. and Cadogan, J. W. (2013), "Conceptualising Town Centre Image and the Customer Experience", Journal of Marketing Management, Vol. 29 No. 15-16, pp. 17531781.

Hart, C., Stachow, G., Rafiq, M. and Laing, A. (2014), "Customer experience of town centres", ESRC report, Loughborough University, Loughborough.

Herhausen, D., Binder, J., Schoegel, M. and Herrmann, A. (2015), "Integrating Bricks with Clicks: Retailer-Level and Channel-Level Outcomes of Online-Offline Channel Integration”, Journal of Retailing, Vol. 91 No. 2, pp. 309-325.

Hoffman, D. L., and Novak, T. P. (2015), "Emergent experience and the connected consumer in the smart home assemblage and the Internet of things". The Center for the Connected Consumer; The George Washington University School of Business.

Holder, J. (2019), "High Street Crisis Deepens: 1 in 12 Shops Closed in Five Years", BBC, 30 January, available at: https://www.theguardian.com/cities/ng-interactive/2019/jan/30/high-streetcrisis-town-centres-lose-8-of-shops-in-five-years (accessed 17th March 2019).

Housing, Communities and Local Government Committee (2019), "High Streets and Town Centres in 2030", House of Commons, available at https://publications.parliament.uk/pa/cm201719/cmselect/cmcomloc/1010/fullreport.html\#heading-6 (accessed 03 March 2019).

Inman, J.J. and Nikolova, H. (2017), "Shopper-facing retail technology: a retailer adoption decision framework incorporating shopper attitudes and privacy concerns", Journal of Retailing, Vol. 93 No. 1, pp. 7-28.

Jain, R., Aagja, J. and Bagdare, S., (2017), "Customer experience-a review and research agenda", Journal of Service Theory and Practice, Vol. 27 No. 3, pp. 642-662.

Jocevski, M., Arvidsson, N., Miragliotta, G., Ghezzi, A., and Mangiaracina, R. (2019), "Transitions towards omni-channel retailing strategies: a business model perspective", International Journal of Retail \& Distribution Management, Vol. 47 No. 2, pp. 78-93.

Kim, Y.K. (2002), “Consumer value: an application to mall and Internet shopping”, International Journal of Retail \& Distribution Management, Vol. 30 No. 12, pp. 595-602. 
Lemon, K. N. and Verhoef, P. C. (2016), "Understanding Customer Experience and the Customer Journey”, Journal of Marketing, Vol. 80 Special Issue, pp. 69-96.

Loughborough University (2019), "Facts And Figures 2019-20", available at: $<$ https://www.lboro.ac.uk/media/media/services/planning/documents/facts-and-figures-1920.pdf $>$ (accessed 06 January 2020).

Morgan, D. L. (1997), Focus groups as qualitative research, Sage, Newbury Park, CA.

Neslin, S. a., Grewal, D., Leghorn, R., Shankar, V., Teerling, M. L., Thomas, J. S. and Verhoef, P. C. (2006), "Challenges and Opportunities in Multichannel Customer Management", Journal of Service Research, Vol. 9 No. 2, pp. 95-112.

Palmatier, R.W., Sivadas, E., Stern, L.W. and El-Ansary, A.I. (2020), Marketing Channel Strategy: An Omni-Channel Approach, 9th ed., Routledge, London.

Pantano, E., and Timmermans, H. (2014), "What is smart for retailing?", Procedia Environmental Sciences, Vol. 22, pp. 101-107.

Pauwels, K. and Neslin, S. A. (2015), "Building With Bricks and Mortar: The Revenue Impact of Opening Physical Stores in a Multichannel Environment”, Journal of Retailing, Vol. 91 No. 2, pp. 182-197.

Puccinelli, N. M., Goodstein, R. C., Grewal, D., Price, R., Raghubir, P. and Stewart, D. (2009), "Customer Experience Management in Retailing: Understanding the Buying Process", Journal of Retailing, Vol. 85 No. 1, pp. 15-30.

Portas, M. (2011), "The Portas Review: An independent review into the future of our high streets", Department of Business, Information and Skills, London, available at: at: https://www.gov.uk/government/publications/the-portas-review-the-future-of-our-highstreets (accessed 08 Feb 2019).

Rigby, C (2020), "How are online and store sales are changing as we emerge from Covid-19 lockdown? Research findings from IMRG, BRC, ONS, Forrester and RetailX", Internet Retailing, available at: https://internetretailing.net/covid-19/covid-19/how-are-online-and-store-sales are-changing-as-we-emerge-from-covid-19-lockdown-research-findings-from-imrg-brc-ons forrester-and-retailx-21625 (accessed 29th October 2020)

Rigby, D. (2011), “The future of shopping”, Harvard Business Review, Vol. 89 No. 12, pp. 65-76.

Stein, A. and Ramaseshan, B. (2016), "Towards the identification of customer experience touch point elements", Journal of Retailing and Consumer Services, Vol. 30, pp.8-19.

Stocchi, L., Hart, C. and Haji, I. (2016), "Understanding the town centre customer experience (TCCE)", Journal of Marketing Management, Vol. 32 No. 17-18, pp. 1562-1587.

Taylerson, R. (2017),“Why Should We Move To Loughborough?”. Leicestershire Live, available at: $<$ https://www.leicestermercury.co.uk/news/property/should-move-live-loughborough249462> (accessed 06 January 2020).

Terblanche, N.S. (2018), "Revisiting the supermarket in-store customer shopping experience", Journal of Retailing and Consumer Services, Vol. 40, pp. 48-59. 
Verhoef, P. C., Kannan, P. K. and Inman, J. J. (2015), "From Multi-Channel Retailing to Omni-Channel Retailing. Introduction to the Special Issue on Multi-Channel Retailing", Journal of Retailing, Vol. 91 No. 2, pp. 174-181.

Verhoef, P. C., Lemon, K. N., Parasuraman, A., Roggeveen, A., Tsiros, M. and Schlesinger, L. A. (2009), "Customer Experience Creation: Determinants, Dynamics and Management Strategies", Journal of Retailing, Vol. 85 No. 1, pp. 31-41.

Verhoef, P. C., Neslin, S. A. and Vroomen, B. (2007), "Multichannel customer management: Understanding the research-shopper phenomenon", International Journal of Research in Marketing, Vol. 24 No. 2, pp. 129-148.

Watson, A., Alexander, B. and Salavati, L. (2018), "The impact of experiential augmented reality applications on fashion purchase intention", International Journal of Retail \& Distribution Management, doi: 10.1108/IJRDM-06-2017-0117.

Wrigley, N., Lambiri, D., Geofutures, G. A., Thurstain, M., Geofutures, -Goodwin and Wood, S. (2015), "British High Streets: from Crisis to Recovery? A Comprehensive Review of the Evidence British High Streets", University of Southampton/Economic and Social Research Council (ESRC), Southampton, pp. 1-105. 


\section{Reviewers' Comments to Author:}

Reviewer: 1

\section{Recommendation: Major Revision}

We would like to thank both reviewers for their valuable insights, which encouraged the author team to carefully reflect and reconsider the structure, shape, and contribution of the paper. We have addressed your comments and answers to additional questions. We feel the paper has benefitted significantly from your review. Based on your suggestions, we have reworked the title of the paper to make it fit with our contributions and direction of the paper.

\section{Comments:}

I feel disappointed that I can't be more positive about this paper. its well written and has a good grasp of town centre decline and previous work on digital connections. I was very interested to see what the paper would recommend after its focus groups to help save the town centre in the future. My disappointment comes from the recommendations around having a decent website to give route guidance and up to date information on who is present, and to make wi-fi available across the centre (plus maybe charging points etc). They seem quite obvious to me and I wonder how common it is not to find at least some digital connections around the UK - I think the spatial variability in this is very high. I know some town centres have good websites already (even Loughborough actually - you can search by location or shop type through its mapping app).

Thank you for your valuable insights. We have reconsidered the analysis, refocused the paper and in doing we hope you will agree, arrived at more substantive recommendations. These look at the opportunities offered by digital integration to support long term survival for towns. [page $13-14$ ].

I thought the digital connection was going to follow some of the more sophisticated procedures we have seen individual companies do but that did not happen. So I am left feeling that this does not take us much beyond very 'obvious' recommendations. In the discussion there are lots of reference made to consistency with previous research - so what is new here? It can't be just a good website and better connectivity Nor, sadly, can I see what the authors could do to increase the contribution given the focus groups are over. However, they should at least discuss the 'richness of their insights' into this wider literature in the discussion

We would like to thank the reviewer for this feedback. We have re-examined respondents' comments and sought to use rich data to reveal the more substantive implications from the study. Customer experience literature emphasises the need to use qualitative data as a first step towards understanding the components of customer experience and its implications (Homburg et al., 2015; Stein and Ramaseshan, 2016). Whilst digital integration is evident at retailer and department stores level, the town centre digital presence remains ambiguous. Given that most town centre demographic had limited awareness of such integration, focus groups allowed participants to share and develop their perceptions towards this concept, which will provide more insightful findings of their expectations of digital integration in towns, leading to important managerial implications as included in page 12-15. . Agreed, participants recommendations might seem obvious, yet the quality and consistency of delivering these recommendations is rather limited for towns. While some towns have created websites and social media pages, the content falls short of consumer expectations. In this study, we touch on specific content relevant to several touchpoints (such as assortment, parking and leisure offer), which are needed to support consumers through their customer journey. 
3. Methodology: Is the paper's argument built on an appropriate base of theory, concepts, or other ideas? Has the research or equivalent intellectual work on which the paper is based been well designed? Are the methods employed appropriate?: Fine - its a standard focus group approach

Thank you for your feedback. To further support previous comments, we have added consideration of how thematic analysis helps to enrich understanding of existing theories [page 6-7].

4. Results: Are results presented clearly and analysed appropriately? Do the conclusions adequately tie together the other elements of the paper? The results are described well but the hype of the introduction is not really matched by the reality we get.

Thank you for this comment. We have substantially changed the discussion of the results in order to address this point. A new structure has been used to address research questions specifically and to clarify the important point about the introduction not matching the results [page 7 to 11].

5. Implications for research, practice and/or society: Does the paper identify clearly any implications for research, practice and/or society? Does the paper bridge the gap between theory and practice? How can the research be used in practice (economic and commercial impact), in teaching, to influence public policy, in research (contributing to the body of knowledge)? What is the impact upon society (influencing public attitudes, affecting quality of life)?

Are these implications consistent with the findings and conclusions of the paper?: there is a good practical section - but the suggestions boil down to two main action points which are very general and I am sure have been thought about by many proactive town centre management teams

Thank you for the valuable comment. We have addressed this point by revising the presentation of the discussion and implications of the study. A new section 'Discussion and implications: Digital integration - where are we now?' sets out challenges and opportunities town centres are facing and how they can address many of these issues. The discussion focuses on 3 key areas 1) Bridge the gap 
between digital and physical channels; 2) Harnessing the potential of digital integration; Create a pull effect using digital channels to drive patronage [p13-15].

6. Quality of Communication: Does the paper clearly express its case, measured against the technical language of the field and the expected knowledge of the journal's readership? Has attention been paid to the clarity of expression and readability, such as sentence structure, jargon use, acronyms, etc.: Yes - it is well written

Thank you for these positive comments regarding the written style and presentation 


\section{Reviewers' Comments to Author:}

Reviewer: 2

\section{Recommendation: Major Revision}

We would like to thank the reviewer for their valuable comments. We have considered your valuable comments and modified the paper accordingly. Based on your comments, we have addressed the role of shopping goals in our findings (page 12). We feel that the paper benefited significantly from your feedback. Following your suggestions, we have made significant changes to the presentation of the findings and modified the title of our paper to fit our contributions.

\section{Comments:}

My suggestion is that this needs further work before publication. As it stands it is not substantive enough to justify publication.

This could be a) deeper exploration of the role of the goal of the shoppers in the types of digital integration b) another set of focus groups in another geography to suggest how generalisable the findings are c) development of the hypotheses (and perhaps tested) to quantify the observations.

Thank you for your comments and suggestions. Based on these, we have made substantive changes to the paper: re-structured presentation of the results and refocused the discussion to focus on the emerging findings and the overall contribution of the study more strongly. We have added to the literature the significance of shopping goal. In terms of the generalisability of the findings, in this study, we aimed to understand how customers perceive digital integration in town centres, and the implication on patronage. As such, focus groups with consumers from various demographics is considered a good fit to deliver rich and insightful data. We understand the need for further geographical consideration to extend the result and have acknowledged this as a limitation of this work. Having said that, we also explain how the participants have lived and experienced various towns beyond the town where they currently reside. As such, the data was rich as it allowed participants to share their experiences beyond the investigated town. In terms of quantitative analysis, this study serves as an exploratory study for an emerging concept in customer experience literature. Thus, we conformed to the literature and adopted a qualitative approach to fit the latent nature of the customer experience construct. As a future work, we agree with your point and have acknowledged the need to provide quantitative evidence for the arguments made in the discussion section.

We have extracted from the rich data sets further implications and meaning and have added a new discussion section 'Discussion and implications: Digital Integration in Town Centres- where are we now?' [p12 to 14]. In this section we focus on how towns can enhance shopper journeys through digital integration to ensure long term survival. Importantly, the study notes an underlying assumption that digital technologies will enhance shopper journeys without direct intervention by town centre management and then discusses the opportunities to harness the potential of digital integration.

\section{Additional Questions:}

\section{Originality: Does the paper contain new and significant information adequate to justify} publication?: The study reported is intrinsically interesting but as presented is somewhat one dimensional. The RQs pose questions that we do not necessarily know the answer to but it is quite light in content for a journal paper.

So it does contain new information but I feel it needs more depth for publication 
Thank you for your comment. We have re-structured the paper to explicitly address the RQ's in the results section [pages $7-12$ ].

2. Relationship to Literature: Does the paper demonstrate an adequate understanding of the relevant literature in the field and cite an appropriate range of literature sources? Is any significant work ignored?: No this seems quite extensive

Thank you for this feedback. We appreciate your comment. Following your suggestion, we have added to the literature review to support and enable exploration of shopping goals in the discussion of the results. (Puccinelli et al., 2009; Palmatier et al., 2020).

3. Methodology: Is the paper's argument built on an appropriate base of theory, concepts, or other ideas? Has the research or equivalent intellectual work on which the paper is based been well designed? Are the methods employed appropriate?: Yes this is well argued. However the sample is small and I feel it does not have sufficient depth. For example: the shopping goals have not been explored and this surely would have impacted upon consumers experiences and therefore the results. Ignoring this important aspect undermines the quality of the work.

We thank you for these important comments and have re-examined the results to add further depth and discussion of shopping goals in relation to our study [pages 4-7].

4. Results: Are results presented clearly and analysed appropriately? Do the conclusions adequately tie together the other elements of the paper?: The results section reads well. However I would have liked to see some linking back to the original research questions to demonstrate unequivocally that these have been answered.

Thank you for your valuable suggestions. We have created stronger links to the research questions to show how these have been answered [pages 7 to 12].

5. Implications for research, practice and/or society: Does the paper identify clearly any implications for research, practice and/or society? Does the paper bridge the gap between theory and practice? How can the research be used in practice (economic and commercial impact), in teaching, to influence public policy, in research (contributing to the body of knowledge)? What is the impact upon society (influencing public attitudes, affecting quality of life)? Are these implications consistent with the findings and conclusions of the paper?:

c) the commercial implications of providing a holistic town centre experience have not been addressed. Who would be responsible, who would fund it etc. I appreciate these are practical rather than research problems but I would have expected some understanding of this presented in the conclusions.

Thank you for your feedback. In the restructuring of the paper, we have considered the relevance of the holistic town centre experience and the implications for town centre managers in the revised discussion [pages 12 to 14]. We have also added further practical considerations. 
6. Quality of Communication: Does the paper clearly express its case, measured against the technical language of the field and the expected knowledge of the journal's readership? Has attention been paid to the clarity of expression and readability, such as sentence structure, jargon use, acronyms, etc.: There are a few typos and phrases such as digital integration that are not well explored but mostly it is well expressed.

We have clarified use of the term digital integration which we aim to present more clearly throughout the paper as meaning the 'integration of digital and physical channels'. This seeks to bring greater clarity to the use of this phrase.

Thank you for this valuable feedback. We have proof-read and addressed the typos 